\title{
From measurement to management: the influence of IT on service operations
}

Citation for published version (APA):

Walczuch, R. M., \& Bielowski, A. G. (2002). From measurement to management: the influence of IT on service operations. METEOR, Maastricht University School of Business and Economics. METEOR Research Memorandum No. 045 https://doi.org/10.26481/umamet.2002045

Document status and date:

Published: 01/01/2002

DOI:

10.26481/umamet.2002045

Document Version:

Publisher's PDF, also known as Version of record

\section{Please check the document version of this publication:}

- A submitted manuscript is the version of the article upon submission and before peer-review. There can be important differences between the submitted version and the official published version of record.

People interested in the research are advised to contact the author for the final version of the publication, or visit the DOI to the publisher's website.

- The final author version and the galley proof are versions of the publication after peer review.

- The final published version features the final layout of the paper including the volume, issue and page numbers.

Link to publication

\footnotetext{
General rights rights.

- You may freely distribute the URL identifying the publication in the public portal. please follow below link for the End User Agreement:

www.umlib.nl/taverne-license

Take down policy

If you believe that this document breaches copyright please contact us at:

repository@maastrichtuniversity.nl

providing details and we will investigate your claim.
}

Copyright and moral rights for the publications made accessible in the public portal are retained by the authors and/or other copyright owners and it is a condition of accessing publications that users recognise and abide by the legal requirements associated with these

- Users may download and print one copy of any publication from the public portal for the purpose of private study or research.

- You may not further distribute the material or use it for any profit-making activity or commercial gain

If the publication is distributed under the terms of Article $25 \mathrm{fa}$ of the Dutch Copyright Act, indicated by the "Taverne" license above, 


\title{
From Measurement to MANAGement:
}

\section{THE INFLUENCE OF IT ON SERVICE OPERATIONS}

\author{
NOVEMBER 2002
}

Alexander Bielowski, Maastrich Macluhan Institute, Postbus 616, 6200MD Maastricht, The Netherlands, Tel: +3143-3883452; Alexander.Bielowski@mmi.unimaas.nl.

Rita Walczuch, Department of Accounting and Information Management, University of Maastricht, Postbus 616, 6200MD Maastricht, Tel: +31-43-3883724; Fax: +31-43-3884876; R.Walczuch@,berfin.unimaas.nl.

\begin{abstract}
The state of service management practice and the developments in IT-efficiency research prompt the call for managerial relevance, normative theory building and the conceptualization and measurement of the impact of Information Technology (IT) on service efficiency. Drawing on theoretical insights from economic and behavioral literature, this article deduces a work system centered model of the service outlet and proposes a measurement methodology (ITIMPACT) geared towards the development of a business intelligence tool. The measurement follows a two-step methodology that first assesses compared-to-best efficiency, using Data Envelopment Analysis (DEA), and subsequently explains efficiency differences using a regression framework. An inter-disciplinary approach bases the first step on econometric logic, while the second takes its foundation in behavioral sciences, and information system research.
\end{abstract}




\section{INTRODUCTION AND CONTRIBUTION}

The service sector accounts for an ever-larger GDP share in today's developed economies. It is apparent that IT is playing an increasingly important role in providing high quality services in an efficient way. Financial transaction processing and loan approval systems in banking, and computer enhanced cash registers or point of sales systems (POS) in retailing are commonplace. Traveling sales representatives or customer service agents with laptop and mobile phone, with direct access to their companies' Intranets from any location are a common sight.

Yet, contemporary academic literature still questions the economic viability of this development. Productivity increases resulting from IT investments elude detection, especially in the service sector, a phenomenon frequently referred to as the productivity paradox of information technology (Brynjolfsson 1993). This situation may result from weak measurement methodology, rather then a real shortcoming in efficiently applying IT in service operations.

Apart from academia, service management is dependent on well-fitted measurement tools for decision support. Computers and communication systems are not mere addition to the capital used in operations. Considered to be a general-purpose technology, IT should have a fundamental impact on the way work is done. The question moving service management is consequently: how to make optimal use of IT in service operations.

The state of research in the field of IT productivity and the needs of service managers alike demand the conception of a measurement methodology tailored to service operations. This methodology should be able to uncover the influence on service efficiency of both IT capital and related management action, esp. business policies.

A measurement methodology based on Data Envelopment Analysis (DEA), a non-parametric estimation of compared-to-best efficiency, enhanced by a second-step regression of explanatory variables on the efficiency scores is believed to enable direct managerial advice, and the development of normative theories of how IT can enhance the service process. First, a short but thorough inquiry into the existing body of literature on IT productivity and related service specific studies identifies the state of knowledge and concludes by explaining why prior research was illsuited to uncover a clear positive effect of IT on service efficiency. Second, the special properties of services, compared to physical production economics, are used to derive methodological requirements. Guided by a work system centered theory, this section establishes the unit of analysis, variable space, and preferred type of productivity measurement. The third section introduces the measurement methodology, including a primer on DEA, and explains its application in general terms. Fourth, a caveat on data quality is given, based on the lessons learned during the first 
application of the methodology. Finally, a qualitative follow-up research is proposed that would lever the contributions made by this measurement methodology in the design of best practice service processes.

The authors are confident of the dual potential of the presented methodology. On the one hand to extend our knowledge beyond episodic evidence of case studies and the assessment of general productivity relations to an understanding of the effect IT and associated properties of the work system can have on the efficiency of service operations. On the other hand providing case specific advice to service management concerning the optimal resource mix and orchestrated business policies, which can be easily implemented through the identification of benchmark units. In this function the methodology might develop to a business intelligence tool. To yield a measurement tool providing managerial relevant insight is an explicit objective of this research.

\section{LITERATURE}

In the young field of IT efficiency research not a single tradition can be identified. The studies are too diverse in their choice of unit of analysis, their methodology and their theoretical underpinning. The latter is spanning from macroeconomics (Roach 1989) to behavioral sciences (Culpan 1995). Only the notion of the "productivity paradox", and the considerable efforts spent in reinforcing it (Dos Santos and Mauer 1993;Morrison and Berndt 1990) and resolving it (Barua, et al. 1995;Brynjolfsson and Hitt 1994;Brynjolfsson and Hitt 2000;Dewan and Min 1997) represent a center of gravity. It can be observed that the level of analysis developed over time from macro-level to firm level and further to sub-firm level. Whereas the subunit and process level research represent the first service specific productivity studies.

\section{The Productivity Paradox}

Solow (Solow 1987) formulated the most often cited "definition" of the productivity paradox of information technology: "we see the computer age everywhere except in the productivity statistics". The paradox was established by macro-economic logic (Roach 1989) and is most likely a result of the adjustment period that is needed for general-purpose technology to show economy wide effect or a result of mismeasurement, i.e. the over-adjusting tendency of computer price deflators. Services (i.e. white collar workers) were said to be worse off. For an exhaustive discussion of the paradox in general, the interested reader is referred to Brynjolfsson (Brynjolfsson 1993), for a service specific discussion to Quinn (Quinn 1996). 
Later studies on firm level, using larger samples over longer time periods and methodologies derived from econometric theory, were able to reject the PPIT. Most studies used data from the International Data Group (IDG) and Compustat II (Brynjolfsson and Hitt 1994;Brynjolfsson and Hitt 2000;Dewan and Min 1997;Lin and Shao 2000). They found significant effect of IT capital on productivity. Predominant methodology is the parametric estimation of production functions, Cobb-Douglas (Brynjolfsson and Hitt 1994) or CES-translog (Dewan and Min 1997) specifications. The estimated substitution elasticity in the CES-translog specification was near unity, thus supporting the assumptions inherent in the Cobb-Douglas specification. Similar findings are consequently all but a surprise. These studies were not able to establish significant industry differences, but gave some indication that manufacturing is better positioned to take advantage of IT capital then services. Chan (Chan 2000) provides a comprehensive discussion of the paradox and its resolution.

Barua et al. (Barua, et al. 1995), using different data and methodology, are credited for enhancing this approach by the assessment of intermediate metrics. Unfortunately their data set was exclusively focused on manufacturing. Their findings corroborate the notion that computers have a positive impact on financial performance, as do the results of Sircar et al (Sircar, et al. 2000). This latter research, applying a gestalt approach, established considerable industry differences.

\section{Service Specific Studies}

In the paradox era, services were said to be even worse off than manufacturing (Brynjolfsson 1993). A notion heavily contested by Quinn (Quinn 1996). Research on IT efficiency, however, is scarce. This is surprising, given the high share of services in today's developed economies ${ }^{1}$, and the strong service orientation in general. Rust (Rust 1998), for example, reasons that all products are really services, the physical product being an important part of the service, rather than vice versa; as does Bitner et al. (Bitner, et al. 2000), who emphasize the fact that virtually all firms compete on the basis of customer service and service offerings. Additionally, the latter highlight the absence of technology focus in service research.

Several studies successfully applied the sub-unit (service outlet) as unit of analysis. Reardon et al. (Reardon, et al. 1996) used financial and physical (quantities) input measures, and value-added in two production function

${ }^{1}$ In the USA, for example, the GDP-share of services in 2000 was $78.1 \%$ if government is included (BEA 2001). 
estimations. Overall, this research identified IT as a highly productive factor in retailing, suggesting that IT contributes as much on the margin as spending on additional selling space.

Using Data Envelopment Analysis (DEA), Banker et al. (Banker, et al. 1990) identified significant impact on efficiency after the introduction of enhanced cash registers to a fast-food chain. The effect was contingent on operating conditions, namely the percentage of breakfast sales.

Many benchmarking studies used DEA in a banking setting. Some incorporated computer terminals as input measurement, measured either in quantity units (Oral and Yolalan 1990;Parkan 1987;Vassiloglou and Giokas 1990) or access time (Soteriou and Zenios 1999;Soteriou and Stavrinides 1997;Zenios, et al. 1999). Collectively these studies proved the usefulness of DEA in a service setting and form a firm foundation on which this research is built. Their outline as benchmarking studies, however, prevented them from making generalized statements concerning the impact of the IT investments on efficiency. Their focus was on the possible improvements.

Mukohpadhyay et al. (Mukhopadhyay, et al. 1997) used the individual application as unit of analysis in order to alleviate complexity. The results indicate that the application under observation (a toll collection system) had considerable impact on complex tasks (not passenger cars), but no considerable impact on simple transactions (passenger cars); where employees knew typically all needed information by heart within the first few days in employment.

Taken together, prior IT productivity research give ample evidence that computers are pulling their weight in manufacturing industries and are likely to have some positive effects in service operations as well. Methodological diverse these studies are myopic towards service and suffer several shortcomings, which are discussed below.

\section{Further Contributing Studies}

Although not directly linked to performance, some studies establish important concepts for explaining differences in performance. They can be considered early stage research in different fields that could extend to the economic realm by incorporating performance measures.

Hitt and Brynjolfsson (Hitt and Brynjolfsson 1997) measured the combination of IT investment and the establishing of a work system. „Overall (the authors) find that information technology is broadly related to a work system that emphasizes decentralized authority and supporting practices such as teamwork, subjective incentives, and increased level of skill and training in the work force (p.82).“ 
Davis (Davis 1989), an example from the IS success measurement literature, developed perceptional measurements of usability and ease of use and correlated them with the actual usage. For comparison with other related measurements, please refer to Garrity and Sanders (Garrity and Sanders 1998).

Culpan (Culpan 1995) studied attributes of end-users on a balanced sample of both manufacturing and service firms. Comparing the learning (interest, means and obstacles), attitudes and purpose of use between employees in manufacturing and service industries, significant differences were identified. This finding from the realm of behavioral studies, together with the findings of Sircar et al. (Sircar, et al. 2000), a performance study, stands in contrast to economic studies that found only weak support for inter-industry differences (Brynjolfsson and Hitt 1994;Dewan and Min 1997).

\section{Conclusion}

The diverse patchwork of IT-efficiency research and IT related service research is hard to grasp in its totality, as is the field of inquiry. Too diverse are the studies, too different the theoretical angles chosen, too inconclusive the findings (Chan 2000). The complexity and inter-disciplinary nature of the phenomena under study most likely inhibited the attempt of a holistic approach. The present research attempts to alleviate this problem by virtue of a disciplinary diverse approach with conceptual contributions from marketing, behavioral science, service management, information systems research, and econometrics.

\section{Shortcomings of Previous Productivity Studies for Services}

The PPIT is solved for manufacturing, but evidence in service is scarce. In the paradox era services were said to be worse off, a belief that lives on today. It is likely that this belief results from shortcomings of prior research: first, the identification of reasonable output units for services is difficult; second, services were underrepresented in the samples; third, the data ignores intangible benefits, such as unmeasured quality gains; and fourth, no attempt was made to explain how efficiency differences came about.

In national databases, service output is frequently approximated by inputs, because of the difficulty in measuring output in the service industry (Quinn 1996). This procedure results in zero productivity growth by definition. Together with the over adjusting tendency of computer price deflators (Brynjolfsson 1993;Brynjolfsson and Hitt 1994;Quinn 1996) and the higher IT intensity in service industries (Dewan and Min 1997), the shortfall of evidence 
in macro-level studies can be explained. The problem persists in firm level studies that also drew their data from national databases. In the case of financial services, this problem is so severe that they were deleted from the samples (Brynjolfsson and Hitt 1994;Dewan and Min 1997).

In addition, services were underrepresented. National databases cover only $42 \%$ of service employment (Quinn 1996), the samples used by Brynjolfsson and Hitt (Brynjolfsson and Hitt 1994), and Dewan and Min (Dewan and Min 1997) contained non-service industries in fractions of $71.5 \%$ and two third respectively. Overall, these production function based firm-level studies did not find significant industry differences, but firm specific differences were significant. Given the under representation of services in their sample and the input related output measurements, services are neutral to the overall estimation, if the strong firm differences in non-service industries are normally distributed. If the firm differences in the non-service sectors are skewed towards the more productive, which appears likely (given the overall positive effect of IT), services will appear to be worse off. In a nutshell, services are poorly measured and these measures are used in a methodology that averages over observations, resulting in measured poor performance.

Intangible benefits from IT investments are said to be substantial, even if not explicitly assessed (Brynjolfsson and Hitt 2000;Brynjolfsson and Yang 1998; Quinn 1996). Mere counting is consequently not enough; an assertion that is further supported by the primary motivation for IT investments. In a survey reported by Brynjolfsson (Brynjolfsson and Hitt 2000) the top three reasons were: improve customer service, target new customers, and improve quality, all of which evade measurement on firm level, as soon as several competitors develop IT capabilities. In general, intangible benefits that result from IT can dissipate to other stakeholder then capital owners, for example in form of better work environments, more rewarding jobs, or quality gains and higher responsiveness that do not result in higher prices if competed away. In services, where the production technology is represented by highly interactive service processes and the product itself in intangible, this problem might be even worse than in non-service operations. The shortcoming of leaving intangible fractions of the output mix unassessed persists even in service specific sub-firm level studies.

Strikingly, all prior studies share the common tenor that computers are more than just capital, they are part of a work system innovation, yet no study investigated how productivity changes came about. Side investments in organizational change, also referred to as adjustment cost, can be considered intangible assets and the estimations of Brynjolfsson and Yang (Brynjolfsson and Yang 1998) result in a market value of up to $18 \$$ per dollar invested in IT. 
Although recent stock price developments might have readjusted this valuation of "IT goodwill" downwards, the typical ratio of 1 to 4 and sometimes 1 to 10 of IT capital investment to investments in consulting services and organizational change clearly point to the fact that there is much more to fostering productivity through IT then just buying computers and hiring IT professionals. In order to uncover the true potential of computers and communication systems it is crucial to supplement the measurement of IT input and change in output by an investigation into the interrelation between IT and the overall work systems of decision authority, incentives and knowledge and skill (Hitt and Brynjolfsson 1997).

Concluding from the above, the authors agree with Hitt and Brynjolfsson (Hitt and Brynjolfsson 1997) that "It may be possible to get stronger results by targeting specific industries that would allow very specific work systems analysis and a finer partition of the uses of IT (p.98)." This is especially true for service that distinguish itself from other industries through heterogeneous production technologies, intangible products and the fact that production and consumption are inseparable. The advance in academic knowledge and the demands of service management can only be accommodated by the development of a service specific methodology that allows to measure productivity differences and explains them in terms of the work system, i.e. the managerial determinants of the work system: business policies and selection of inputs with distinctive properties.

\section{METHOdOLOGICAL REQUIREMENTS}

Services are special. Whereas the production of physical goods is a repetitive application of the same production technology, services are produced in interactive service processes that are typically heterogeneous across occurrences. Moreover, the efficiency of physical production is relatively simple to measure, giving rise to rather homogenous production processes across firms. In parametric production function estimations the existence of a single, known production technology is an implicit assumption, apparently violated by most service operations, because of their heterogeneous service processes constitute multiple and unknown production technologies.

Inseparable production and consumption is another specialty of services, thus unequivocally defining the place of value creation to be the interactive service process. Mukohpadhyay (Mukhopadhyay, et al. 1997) chose a single information process as unit of analysis in order to offer detailed insight in the effect of a single application. His arguments are compelling: first, it does not involve aggregation across a large number of complex processes, second, 
it allows to "open the black box", making the effect of IT traceable, and finally investment decisions are often made at application level. Following his rational assessment of IT productivity on process level would be desirable.

\section{Unit of Analysis}

The demand for measurements relevant for managers and directed towards normative theory unfortunately precludes an analysis at this micro level. First, the single process is not the scope of management attention but the realm of service personnel. The rise of enterprise systems, i.e. ERP, has in addition shifted the scope of investment decisions away from the single application. Second, output measurements are rarely recorded at this level, but are crucial for the assessment of productivity, which must constitute the basis of any normative economic theory. Third, processes in service operations are highly interdependent. A single employee typically has a role in a plethora of service processes, and a single workstation typically runs a large number of applications supporting an even larger number of single service processes.

The conceptualization of a service operation as a work system and the single process as a state of this system appears to be powerful if a methodology that measures efficiency differences and explains them in managerial terms is the desired outcome. The unit of analysis of this research is consequently the branch, or service outlet, whether this is a bank branch, a single retail outlet or a team of consultants on assignment. This unit of analysis conveniently coincides with the scope of managerial discretion of service operations management, the management level nearest to the actual place of value creation, the single service process.

The measurements must be assessed at the organizational sub-unit level or below (and subsequently aggregated). An obvious choice of the unit of measurement below the sub-unit level is the individual. In the derivation of measurement concepts, a choice between the two levels could be made. Some variable concepts might be measurable at both levels. In such a case, the assessment at the sub-unit level would be sufficient to fulfill the requirements of the model.

\section{Work System Centered Theory}

Hitt and Brynjolfsson (Hitt and Brynjolfsson 1997) found "(...) that information technology is broadly related to a work system that emphasizes decentralized authority and supporting practices such as teamwork, subjective incentives, and increased level of skill and training in the work force. (p82)". The precedents of these properties are business policies, such as empowerment, leadership style, selection and training. The theory underlying subsequent 
discussions is depicted in figure 1. Inputs enter the service outlet and are made available to the work system, composed of business policies and distinctive properties of the inputs. The work system, of which the states correspond to single service processes, transforms inputs into outputs, constraint by environmental influences. The output of a service process or a collection of sequential processes "materializes" within the service outlet, namely in the front office, where its value is transferred to the customer. Please note, that this theory, which is derived from IT productivity literature, is congruent with the notion of service process blueprinting (Shostack 1984).

\section{Variable Space}

The assessment of efficiency differences between service outlets demands the measurement of inputs and outputs at this level, as the simplest definition of efficiency is a ratio of outputs through inputs. Commonly applied efficiency measures are partial, or single factor efficiency ratios, such as labor productivity; dividing total output by labor input. In order to unveil the effect of IT in the context of a complex work system, multi-factor productivity must be assessed. All inputs that enter the work system must be measured and constitute the first set of variables, IT input being a subset of special interest.

As discussed above, intangible benefits might account for a major fraction of the value created by IT. As a consequence, a collection of output variables should be incorporated, accounting for job satisfaction (Sims, et al. 1976) and customer satisfaction, e.g. SERVQUAL (Parasuraman and Zeithaml 1991), in addition to financial and competition measurements, such as total financial output and market share.

In addition, environmental constraints, i.e. the market potential of the surrounding area, must be assessed and incorporated into the efficiency measurement. They form the third set of variables: environmental control variables.

The assessment of the work system, used to explain differences in efficiency, can be divided into the variables measuring business policies, and input properties. Examples of business policy measurement scales used by the authors are leadership style (House and Dessler 1974), empowerment, and IT training. Input properties subdivide into variables measuring IT properties, e.g. ease of use (Davis 1989), or degree of customization, and work force properties, e.g. knowledge and experience in the applicable domain, or the readiness to embrace new technology in form of the technology readiness index (TRI) developed by Parasuraman (Parasuraman 2000).

Prior research establishing the notion of a work system (Hitt and Brynjolfsson 1997), research of IS success (Davis 1989), attitudes (Culpan 1995) and TRI (Parasuraman 2000), used measures of the actual usage of IT as dependent 
variable. In the above-presented model of service operations, usage is considered to be a property of the service processes, the states of the work system, rather than an output of a determinant of the work system. Usage of IT, and similar measurements, consequently measure service process components.

IT usage, together with the measurements assessing the work system, business policies and input properties, are employed as explanatory variables in order to clarify how differences in productivity came along. Figure 2 offers a graphical summary of the variable space and shows its fit to above presented theory.

\section{Efficiency Measurement}

In order to be meaningful for managers and enabling normative theory building, any methodology must incorporate some measurement of performance. Two main questions with which one needs to deal in this context are first, what type of performance measure to chose and second, which way to assess the chosen measurement, i.e. parametric estimation, or non-parametric calculation.

The definition of efficiency as ratio of outputs through inputs (1) gives rise to the question which dimensionality of inputs and outputs should be chosen: quantities (technical efficiency alias X-efficiency) or monetary value (economic efficiency alias productivity). Lin and Shao (Lin and Shao 2000) present an extensive discussion of technical efficiency as the preferable measure, and conclude that it is "an economic index of organizational performance" that is able to "provide more ample evidence (than other performance measures) to substantiate the contribution that IT may make (pp. 5-6)".

$$
\text { Efficiency }=\frac{\text { Output }}{\text { Input }}
$$

Two economic reasons, in addition to methodological reasons discussed by Lin and Shao (Lin and Shao 2000), support the choice of technical efficiency for academic inquiry. First, equality of relative prices can be assumed, given the notion of quasi-efficient markets, if all assessed units reside in the same national economy. This means that a technical efficiency measure would not deviate significantly from an economic efficiency (productivity) measure. This rationale is, in increasing extent, also applicable to supra-national economic communities (i.e. EU) and freetrade zones (i.e. NAFTA). Second, the existence of benefits that are not recovered by capital owners might include benefits that dissipate to the public. The general public values sustainable growth, a concept that is not assessable by any measurement in the applied variable space. This shortcoming can be dealt with by methodological 
considerations: sustainable growth easily translates in resource consciousness, which is achieved by technical efficient transformation processes. Choosing technical efficiency as performance measurement can thus accommodate the interest of the general public.

In case of a purely managerial application, performance measurement of interest might, however, be productivity or even profitability. In any case it might prove difficult to secure quantity measures, especially in the case of outputs. The measurement methodology should consequently be flexible enough to alternatively allow the measurement of productivity or profitability, not only technical efficiency. Furthermore it should be unit invariant. This means that the methodology should allow to measure inputs and outputs in different units.

As discussed at the beginning of this section, the parametric estimation of production functions is restrictive in so far that it assumes a single, known production technology, because it demands the ex-ante specification of a functional form, e.g. Cobb-Douglas (Brynjolfsson and Hitt 1994;Brynjolfsson and Hitt 2000) or translog (Dewan and Min 1997; Reardon, et al. 1996). Many services exhibit multiple, unknown production technologies because of process heterogeneity. A methodology exclusively focussing on service should be sensible to this fact and consequently accommodate differences in production technology among units while explaining efficiency differences between units. The preferred methodology would, consequently, be non-parametric. Fortunately, Data Envelopment Analysis (DEA) offers all required properties: first, it is a non-parametric estimation able to accommodate multiple and unknown production technologies; second, it is able to handle multiple inputs and outputs, and third, it estimates, in its best-known formulation, compared-to-best technical efficiency. Several previous studies (Banker, et al. 1990; Sherman and Gold 1985;Sherman and Ladino 1995;Soteriou and Zenios 1999;Soteriou and Stavrinides 1997; Vassiloglou and Giokas 1990;Zenios, et al. 1999) demonstrated the merits of DEA in a service setting and included some measure of IT in their input variable sets.

\section{THE ITIMPACT METHODOLOGY}

The requirement to identify and explain efficiency differences, gives rise to a two-step methodology (see figure 3).

First, efficiency differences are computed from the input and output measurements, using DEA. Second, the explanatory variables are used to explain the efficiency differences. 


\section{Primer on Data Envelopment Analysis (DEA)}

DEA is used, first because it is a non-parametric methodology based on fractional linear programming; second, because it is able to deal with multiple outputs, a capability parametric estimations still lack; and third because it provides, in addition to the efficiency score, measurements of possible improvements that are invaluable for management.

DEA assembles a piece-wise, linear, multi-dimensional envelop of the data, the efficient frontier, and measures inefficiency as distance from the frontier. In this way, DEA lets the data speak for itself, rather than forcing the data into a predefined function. The efficiency computed in this way is relative to the best performing units, i.e. service outlets, in the data-set. This concept is known as compared-to-best efficiency, its application in marketing and operations research as benchmarking (Parsons 1994). The units of analysis are called Decision Making Units (henceforth DMU).

DEA was first proposed by Charnes, Cooper and Rhodes (CCR) (Charnes, et al. 1978) for benchmarking DMUs, in their case public sector non-profit organizational units. The CCR-DEA was an input-oriented, constant-return-toscale (CRS) model. Sherman and Gold (Sherman and Gold 1985) are credited to have first applied DEA in a banking setting; banking being among the first profit-oriented sectors in which this technique was applied.

Further refinements of DEA yielded a variable-return-to-scale model (Banker, et al. 1984) and models that are able to incorporate non-discretionary variables (Coelli, et al. 1998). For the understanding of the subsequent discussion it is sufficient to have a closer look at the basic constant-returns-to-scale CCR-model, which is easily extended to the variable-returns-to-scale model through the addition of an intercept term.

The definition of efficiency as represented in equation (1) above is applicable for one output and one input. In case of multiple inputs and/or outputs this ratio extends to the weighted sum of outputs through the weighted sum of inputs. The weights serve a dual purpose. On the one hand they correct for different units of measurements, e.g. square meter and floor space and human hours. On the other hand they give an indication of the relative importance of a particular input or output. The weights are consequently unknown multipliers to be determined in course of the DEA. The efficiency $(\mathrm{E})$ of a specific DMU $(\mathrm{k})$ is given by the following fractional linear program: 


$$
\text { Maximize } \quad E_{k}=\frac{\sum_{r=1}^{s} u_{r k} Y_{r k}}{\sum_{i=1}^{m} v_{i k} X_{i k}}
$$

Subject to:

$$
\begin{aligned}
& \frac{\sum_{r=1}^{s} u_{r k} Y_{r j}}{\sum_{i=1}^{m} v_{i k} X_{i j}} \leq 1 ; \forall j=[1, N] \\
& u_{r k}, v_{i k} \geq \varepsilon ; \forall r, i
\end{aligned}
$$

Where

$Y_{r j}$ is the quantity of output $r$ produced by $D M U j=(1, N)$,

$\mathrm{X}_{\mathrm{ij}}$ is the quantity of input $\mathrm{i}$ used by DMU $\mathrm{j}=(1, \mathrm{~N})$,

$\mathrm{u}_{\mathrm{rk}}$ is the weight (to be determined) of output $\mathrm{r}$ for the DMU $\mathrm{k}$,

$\mathrm{V}_{\mathrm{ik}}$ is the weight (to be determined) of input $\mathrm{i}$ for the DMU $\mathrm{k}$, and

$\varepsilon$ is a very small number (non-Archimedean infinitesimal).

This fractal linear program must be solved for each of the N DMUs separately, yielding $\mathrm{N}$ sets of weights, one for every DMU. The efficiency score $E_{k}=1$ if the DMU is efficient and thus part of the frontier. $E_{k}<1$ if the unit is inefficient.

The weights $\left(\mathrm{u}_{\mathrm{rk}}\right.$ and $\left.\mathrm{v}_{\mathrm{ik}}\right)$ are free to take any value that maximizes the efficiency of DMU $\mathrm{k}$, while being constrained by all DMUs in the sample (including DMU $\mathrm{k}$ ). The $\mathrm{N}$ constraints of this program enforce that the weights assigned to DMU k would not result in an efficiency score higher than 1, if assigned to any other DMU. A DMU is efficient $\left(E_{k}=1\right)$ if it is able to produce the same outputs with less in at least one input (input orientation) than the other DMUs in the sample; or if it is able to produce more of at least one output (output orientation) given the same inputs as the other DMUs in the sample. The efficient DMUs define the efficient frontier. The inefficiency $\left(\mathrm{E}_{\mathrm{k}}<1\right)$ of DMUs that 
are not part of the frontier is measured as the distance between the inefficient DMU and the frontier. The distance can also be interpreted as a possible path an inefficient DMU can take in order to become efficient.

A simple one input (i), one output (r) example of a CRS-model is shown in figure I. The one input, one output case is taken for representation purposes. The model is able to deal with multiple inputs and multiple outputs measured in different scales. Two of the four DMUs represented in figure I (A,B,C,D) are efficient (A and D) and thus define the frontier; their efficiency score equals 1. DMU B is inefficient $\left(E_{k}<1\right)$ compared to DMU D. DMU D is called the “peer" of DMU B. The inefficiency is computed as the distance of DMU B from its peer DMU D. In most cases, not one single peer can be identified for an inefficient DMU, but rather a group of peers, called "reference set". This is the case for DMU C in figure 4. In such a case, a virtual unit (C'), henceforth virtual comparison unit (VCU), is computed as the linear combination of the peers in the reference set. The weights $(\lambda)$ of the peers that make up a VCU are also outputted by the DEA. By comparing the actual inputs and outputs of the inefficient DMU (i.e. C) with the optimal inputs and outputs of the VCU (i.e. C'), possible improvements for each input and output can be computed. The concept of a VCU should be understood as follows. The VCU (i.e. C') represents the position the inefficient DMU (i.e. C) can reach by “imitating” best practice as defined by the efficient peers (i.e. A and D).

Please note that, in order to solve the fractional linear program presented above, it must be transformed into a linear program. In general the dual formulation is solved, directly yielding the peer-weights $(\lambda)$. For a comprehensive explanation of the transformations, please refer to Oral and Yololan (Oral and Yolalan 1990) a more complete discussion is presented by Coelli, Rao, and Battese (Coelli, et al. 1998).

Up to now, only DEA formulations were discussed that compute technical efficiency. This means that inputs and outputs are measured in quantity units, rather than monetary value. DEA can be adapted to measure productivity (monetary units of inputs and outputs) or profitability (inputs and outputs measured in quantity units and supplemented with input and output prices) rather than technical efficiency, making it a very versatile tool able to accommodate different research objectives, whether managerial of academic.

\section{DEA and Non-discretionary Variables}

Above formulations only accounted for discretionary inputs and discretionary outputs. That is, all variables were assumed to be under the discretion of the DMU (i.e. its manager) and can thus be varied in order to move to the frontier. Several methods were brought forward by econometric literature that account for non-discretionary 
variables, i.e. decisions made at a higher level of management or environmental influences. Two such methods are here discussed: first the incorporation of non-discretionary inputs in the DEA formulation; second, the regression of (non-discretionary) variables on the efficiency-score. It should be noted, that the methodologies are here reported as used in prior research (i.e. the incorporation of environmental controls); while emphasizing their methodological properties.

The first method incorporates the non-discretionary variables directly into the DEA formulation either as input or output. The path an inefficient DMU can take to the frontier is defined by the discretionary variables in the analysis. Non-discretionary variables also enter the analysis, but are fixed at the current level. In other words, the path to the frontier is restricted not to run along dimensions that are non-discretionary. This implies that inefficient DMUs are compared with peers that are most alike the unit under scrutiny in terms of the control variables. Consequently, their effects are directly accounted for in the efficiency scores. This makes interpretation straightforward.

The second approach, also called two-step DEA, runs the DEA only incorporating the discretionary variables. Subsequently the control variables are regressed upon the efficiency scores. Ordinary least square (OLS) can be applied $^{2}$. The regression coefficients give an indication of the direction and the magnitude of the influence. It is important to note that this comes with a considerable disadvantage: The efficiency scores are not directly fit for further analysis, because they are not adjusted. Coelli, Rao, and Battese (Coelli, et al. 1998), state that "(t)he secondstage regression can be used to "correct" the efficiency scores (...) by using the estimated regression coefficients to adjust all efficiency scores to correspond to a common level of environment (p. 170)". The quality of these adjusted scores is debatable; the validity of the regression coefficients is not. The methodology proposed in this article applies the two-step approach without correcting the efficiency scores in its investigation of explanatory variables.

\section{First Step: Measuring Efficiency Differences}

The first step uses a DEA formulation that incorporates both discretionary and non-discretionary variables able to adjust for environmental influences, such as the market potential of the surrounding, as long as they are measured by continuous variables (Coelli, et al. 1998). The number of inhabitants and the number of businesses are measurements

${ }^{2}$ If the number of efficient units is large, OLS might yield estimates above one, because of the large fraction of ones in the efficiency scores. In such a case, Tobit regression is preferable, as it can account for truncated data. 
of market potential that fulfill this requirement. In the DEA analysis, such environmental controls are treated as nondiscretionary inputs (figure 3).

The second type of non-discretionary variables is called firm controlled inputs. The degree of discretion in a particular situation is dependent on the hierarchical level that is assessed. The choice of the service outlet as unit of analysis and service operations management as assessed hierarchical level means that input decisions taken at higher level, i.e. top management at firm level, constrain the discretion of the service operations management, hence represent non-discretionary inputs.

The input measurements are classified into IT-input and other inputs, which might differ somewhat between research objects. It is in any case crucial to compose a parsimonious, but complete input set, accounting for labor, IT capital, and other capital.

Taking the example of consumer banking, one can measure the IT-input as quantities of IT hardware that is operational (PCs and servers), and second, of the amount of communication services consumed (e.g. telephone and internet cost). In addition, the amount of IT-labor (in work day equivalents) is incorporated in the measurement of IT input.

Other inputs consist of other capital, labor other than IT-labor, and operating expenses other than the cost of communication services. In the example case of consumer banking, other inputs consisted of total labor input, and square meters of floor space (as viable approximation of capital other than IT (Sherman and Gold 1985)).

Outputs are variables that cannot directly be influenced by managers, making them in fact non-discretionary variables. If secondary influences on these can be assumed to be discretionary, given the marketing approach i.e. advertising and promotion, these variables can be treated as (quasi-) discretionary. As discussed above, the output set should be sensible to intangible benefits not captured by the owners, thus including measurements of job satisfaction and customer satisfaction. The primary output measurement must undoubtedly assess the services produced, whether measured by the value of total service output or the number of provided services. This choice depends on the nature of the provided service. In case of complex services, such as banking, the authors give preference to a value based measurement of total service output, because quality changes might not be detectable in unit based measurements. In case of highly standardized outputs, such as retail or fast-food sales, a unit based measurement is preferable in order to conform with the definition of technical efficiency. 
After the collection of variables, a number of methodological choices must be made, pertaining to scale economies (constant vs. variable), and to the orientation (input vs. output) of the DEA. For further insight, please, refer to textbooks in production economics (Coelli, et al. 1998) and manuals of academic DEA software (Coelli 1996;Scheel 2000). In order to yield efficiency scores that fit to the second step, the radial distance specification should be used. In this way, the efficiency score can be interpreted as percentages.

DEA yields a number of valuable measurements in addition to the efficiency score that is used in the second step of this methodology. The researcher can provide management with a detailed report on DMU level: possible improvements per input or output (depending on the chosen orientation) and the identification of the reference set. This means that the methodology furnishes as "side product" a complete benchmarking analysis.

\section{Second Step: Explaining Efficiency Differences}

The second-step investigates the effect of explanatory variables on the efficiency of branches. The efficiency score derived in the first step is used as dependent variable in a regression, similar to the above presented two-step DEA. Explanatory variables, grouped in work system and process components measurement, are used as independent variables. This is a reasonable use of this approach, because it does not incorporate the correction of efficiency scores. The regression coefficients are interpreted for themselves. The explanatory variables brought forward are all internal to the single DMU. They cannot be considered inputs or outputs, because they do not have the required properties, i.e. they are not used up.

The second step yields regression coefficients, either from one joint regression or from several separate regressions, with positive coefficients pinpointing business policies, input properties and process components exhibiting a positive effect on efficiency. This allows to test hypothesis on the composition of a high performance work system. It is, for example, possible to answer questions like: Has leadership style an influence on service efficiency? Which leadership style is best suited for IT supported service operations, instrumental, supportive or participative leadership? Has the customization of information systems, an IT-property measurement, a positive impact on efficiency, or is it a waste of money?

The application of the measurement instrument enables the explanation of the impact of IT on service process efficiency. This serves a double purpose: First, it allows to develop normative models of service efficiency and to explain how best to use IT. Second, it can give very precise advice to management through its use in benchmarking. 


\section{Unit Homogeneity}

As stated previously, the measurement methodology must be customized to fit the research object. Inputs and output measurements can be specific to a particular service industry or even firm. Furthermore, the degree of managerial discretion at the DMU level must be taken into consideration in order to identify firm-controlled inputs.

Apart from these adjustments, relative unit-homogeneity must be assessed. In general, service outlets of a single firm exhibit a reasonably high degree of homogeneity. This goes so far that some components of the control universe can be assumed to be equal across all units. The consequence is that these measurements can be omitted without further consideration. Because of higher parsimony of the resulting model, the explanatory power is improved. If control variables can be deleted by virtue of unit homogeneity, they always should be deleted.

This logic applies as well to standard operating procedures and capital structure. Management might design standard operating procedures (SOP), however, their implementation, the actual service process, is a function of business policies and input properties (i.e. human resources). SOPs are firm-controlled, because they are typically designed at higher managerial levels and applied to the totality of the multi-site infrastructure. Assessing SOPs at the level of the sub-unit is not needed, because they are the same (standard) for all units. Unit-management, however, has multiple levers to influence the implementation of SOPs. Influencing the implementation are different business policies through their impact on decision authority and incentives. In addition, unit management might attempt to regulate those processes that are not subject of SOPs or it might leave them unregulated. Leadership style scales (House and Dessler 1974), used as explanatory variables, give some indication in how far processes are regulated. A manager that attempts to regulate most processes will score high on instrumental leadership, which is also called leadership through initiating structure. On the other extreme, a participative leader "gives serious consideration to what his subordinates have to say" and "consults with his subordinates before taking action". This means that leadership style gives some indication of the primary location of process innovation. In the first case the primary process innovator is the manager. In the latter case, process innovation originates from the employees.

For service outlets of the same firm, a relatively homogenous structure of capital investments other than IT can often be assumed, as it is mandated by the requirement of a consistent appearance vis-a-vis the customer. A measurement of the magnitude of these investments is thus sufficient. A viable approximation of the magnitude of other capital investment is the physical size of the service outlet in square meters (Sherman and Gold 1985). Apart form being framed in terms of quantity, rather than monetary units, this approximation has an additional effect that is very 
desirable. Many operating expenses, such as heating and lighting, are known to correlate with the size of the outlet, simply because of the laws of physics.

Because the degree of sub-unit management discretion and unit-homogeneity are idiosyncratic properties of the firm that influence the choice of measurements, the two concepts must be assessed before the measurement instrument can be customized to fit the research object. A small-scale exploratory research is needed before the measurement instrument can be applied such as semi-structured interviews with managers at both the top-management and the service operations management level, as used during the first application of ITIMPACT.

\section{Caveat on Data Quality}

It is important to note that the non-parametric nature of DEA comes with a price. The procedure is sensitive to extreme values, because the frontier is constructed from the data at hand. It is thus crucial to control the data for inconsistencies.

The ITIMPACT methodology was first applied to a Belgian multi-site financial service provider. The governance structure customary to this company can simplest be described as franchise. The remuneration of the headquarters is based on a percentage of the (official) financial return. The discretion of the management at outlet level was consequently far reaching and included investment decisions, especially pertaining to IT input, and staffing.

The independence of the operational units was initially thought to be a major advantage of the research object. It became, however, apparent that the HQ did not have any record of the investments at unit level, nor the level of staffing. Questionnaires were distributed to the branches. Apart from the scales measuring business policies, IT usage, job satisfaction, skill and knowledge in banking and demographics, the questionnaire included items asking for the investments and staffing to be filled out exclusively by the manager. It was for example asked: "How many personal computers do you have operational in your branch?" and "Have you invested in network servers? If yes, how many are operational in your branch?"

The responses on input measurements were poor. In some cases several respondents reported on inputs, however, all multiple responses were inconsistent. Respondents reported to have several network servers, however, no PCs. Items were selectively left unanswered. In a nutshell, the input data collected by questionnaire was highly inconsistent and unreliable. We conclude that questionnaires, no matter how carefully formulated, should not be used to collect variables used in non-parametric analysis. 
The perceptional multi-item scales, in contrast, performed exceptionally well. This includes the TRI (Parasuraman 2000), which was designed in a marketing setting and previously not applied to operations research. It is apparent that questionnaires are viable vehicles for the collection of explanatory variable data on business policies, input properties and IT usage used in the regression type second step of ITIMPACT.

In order to secure the consistency and reliability of the data for the first step of ITIMPACT, one should exclusively recur to high quality secondary data. The proliferation of computerized financial information systems, enterprise systems and point of sales systems should make this increasingly easy to achieve. A very promising vision is to integrate ITIMPACT into the enterprise systems of service organizations in form of a business intelligence tool. Such an application could regularly run the first step as performance assessment on a quarterly or even monthly basis. This procedure can be extended to include the second step on a consolidated basis at the end of the fourth quarter in support to strategy formulation. The steps of ITIMPACT correspond thus nicely to the notions of business intelligence systems (first step) and strategic enterprise planning systems (second step).

\section{QUALITATIVE FOLLOW-UP RESEARCH}

As discussed above, service processes are heterogeneous and strongly interrelated and consequently evade quantitative assessment. What is possible is a qualitative assessment of these processes. The measurement instrument conceived in this article is able to serve as foundation for an in-depth qualitative research with unprecedented explanatory power. As in this article, service processes are mostly modeled as black box. Qualitative research allows this black box to be opened. Just opening one box or a randomly chosen set of boxes might be valuable, but can at best give descriptive insight. Normative, qualitative advice, though, would be needed for the design of optimal service processes, i.e. in the course of service process blueprinting (Shostack 1984). This is exactly what the measurement instrument makes possible: it does not only identify the boxes that contain the most efficient processes, it also identifies the conditions under which these processes are efficient (work-system) and gives a first indication of their inner working (IT-usage). 


\section{REFERENCES}

Banker, R., R.J. Kaufmanand R.C. Morey, "Measuring gains in operational efficiency for information technology: a study of the Positran deployment at Hardee' s Inc," Journal of Management Information Systems, 1990, 7,: 2, pp. I29-54.

Banker, R.D., A. Charnesand W.W. Cooper, "Some models for estimating technical and scale efficiencies in Data Envelopment Analysis," Management Science, 1984, 30,: 9, pp. I1078-1092.

Barua, A., C.H. Kriebeland T. Mukhopadhyay, "Information technologies and business value: an analytic and empirical investigation," Information System Research, 1995, 6, : 1, pp. I3-23.

BEA, "Bureau of Economic Analysis homepage," 2001, last accessed: 2001: April, 23, at http://www.bea.gov/.

Bitner, M.J., S.W. Brownand M.L. Meuter, "Technology infusion in service encounters," Journal of the Academy of Marketing Science, 2000, 28,: 1, pp. I138-149.

Brynjolfsson, E., "The productivity paradox of information technology," Communication of the ACM, 1993, 36,: 12, pp. I67-77.

Brynjolfsson, E. and L.M. Hitt, "Paradox lost? Firm-level evidence of high returns to information system spending," MIT Sloan, 1994,,

Brynjolfsson, E. and L.M. Hitt, "Computing productivity: firm-level evidence," MIT Sloan, 2000,,

Brynjolfsson, E. and S. Yang, "The intangible benefits and costs of computer investments: evidence from the financial markets," MIT Sloan, 1998,,

Chan, Y.E., "IT value: the great divide between qualitative and quantitative and individual and organizational measures," Journal of Management Information Systems, 2000, 16,: 4, pp. I225-261.

Charnes, A., W.W. Cooperand E. Rhodes, "Measuring productive efficiency of decision-making units," European Journal of Operational Research, 1978, 2,: 6, pp. I429-444.

Coelli, T., "A guide to DEAP version 2.1: a data envelopment analysis (Computer) Program," Arimdale, Australia, 1996,: 96/08, pp. I1-49.

Coelli, T., D.S.P. Raoand G.E. Battese, An introduction to efficiency and productivity analysis, Kluwer Academic Publishers, Boston, 1998.

Culpan, O., "Attitudes of end-users towards information technology in manufacturing and service industries," Information \& Management, 1995, 28, pp. I167-176.

Davis, F.D., "Perceived usefulness, perceived ease of use, and user acceptance of information technology," MIS Quarterly, 1989, September, pp. I319-340.

Dewan, S. and C. Min, "The substitution of information technology for other factors of production: a firm level analysis," Management Science, 1997, 43,: 12, pp. I1660-1675.

Dos Santos, B.L.P.K.G. and D.C. Mauer, "The Impact of information technology investment announcements on the market value of the firm," Information Systems Research, 1993, 4,: 1 (March), pp. I1-23.

Garrity, J.E. and G.L. Sanders, "Dimensions of information systems success," In Information Systems Success Measurement, J. E. Garrity and G. L. Sanders (Ed.), Idea Group Publishing, Hershey USA, 1998, pp. I1345 . 
Hitt, L.M. and E. Brynjolfsson, "Information technology and internal firm organization: an exploratory analysis," Journal of Management Information Systems, 1997, 14,: 2, pp. I81-101.

House, R.J. and G. Dessler, "The path-goal theory of leadership: some post hoc and a priori tests," In Contingency Approach to Leadership, J. G. Hunt and L. L. Larson (Ed.), Southern Illinois University Press, Carbondale, IL, 1974,

Lin, W.T. and B.B.M. Shao, "Relative size of information technology investments and productive efficiency: their linkage and empirical evidence," Journal of the Association for Information Systems, 2000, 1,: 7 ,

Morrison, C.J. and E.R. Berndt, "Assessing the productivity of information technology equipment in the U.S. manufacturing industries," Working paper 3582, National Bureau of Economic Research, January 1990.

Mukhopadhyay, T., J.F. Lerchand V. Mangal, "Assessing the impact of information technology on labor productivity: a field study," Decision Support Systems, 1997, 19, pp. I109-122.

Oral, M. and R. Yolalan, "An empirical study on measuring operating efficiency and profitability of bank branches," European Journal of Operational Research, 1990, 46, pp. I282-294.

Parasuraman, A., "Technology readiness index (TRI) - A multi-item scale to measure readiness to embrace new technology," Journal of Service Research, 2000, 2,: 4, pp. I307-320.

Parasuraman, A.B., L. L. and V.A. Zeithaml, "Refinement and reassessment of the SERVQUAL scale," Journal of Retailing, 1991, 67,: 4, pp. I420-450.

Parkan, C., "Measuring the efficiency of service operations: an application to bank branches," Engineering Costs and Production Economics, 1987, 12, pp. I237-242.

Parsons, L.J., "Productivity and relative efficiency: past and future?," In Research Traditions in Marketing, G. L. Lilien, G. Laurent and B. Pras (Ed.), Kluwer, New York, 1994, pp. I169-196.

Quinn, J.B., "The productivity paradox is false: information technology improves service performance," Advances in Service Marketing and Management, 1996, 5, pp. I71-84.

Reardon, J., H. Ronand C. Barbara, "The effect of information technology on production in retailing," Journal of Retailing, 1996, 72,: 2, pp. I445-461.

Roach, S.S., "America's white-collar productivity dilemma," Manufacturing Engineering, 1989, August, pp. I104.

Rust, R., "Editorial: what is the domain of service research?," Journal of Service Research, 1998, 1, pp. I107.

Scheel, H., "EMS: Efficiency measurement system - User's manual," 2000, last accessed: 2002: 20. June 1042 AM, at http://www.wiso.uni-dortmund.de/lsfg/or/scheel/ems/ems.pdf.

Sherman, H.D. and F. Gold, "Bank branch operating efficiency - evaluation with data envelopment analysis," Journal of Banking and Finance, 1985, 9, pp. I297-315.

Sherman, H.D. and G. Ladino, "Managing bank productivity using data envelopment analysis (DEA)," Interfaces, 1995, 25,: 2, pp. I60-73.

Shostack, L.G., "Designing services that deliver," Harward Busness Review, 1984,,: January - February, pp. I133139.

Sims, H.P.J., A.D. Szilagyiand R.T. Keller, "The measurement of job characteristics," Academy of Management Journal, 1976, 19 (June), pp. I195-212. 
Sircar, S., J.L. Turnbowand B. Bordoloi, "A framework for assessing the relationship between information technology investments and firm performance," Journal of Management Information Systems, 2000, 16,: 4, pp. I69-97.

Solow, R.M., "We'd better watch out," New York Times Book Review, July 12, 1987, pp. I36.

Soteriou, A. and S.A. Zenios, "Operations, quality and profitability in the provision of banking services," Management Science, 1999, 45,: 9, pp. I1221-1238.

Soteriou, A.C. and Y. Stavrinides, "An internal customer service quality data envelopment analysis model for bank branches," International Journal of Operations \& Production Management, 1997, 17,: 8, pp. I780-789.

Vassiloglou, M. and D. Giokas, "A study of relative efficiency of bank branches: an application of data envelopment analysis," Journal of the Operational Research Society, 1990, 41,: 7, pp. I591-597.

Zenios, C.V., S.A. Zenios, K. Agathocleousand C. Soteriou Andreas, "Benchmarking of efficiency of bank branches," Interfaces, 1999, 29,: 3, pp. I33-51. 


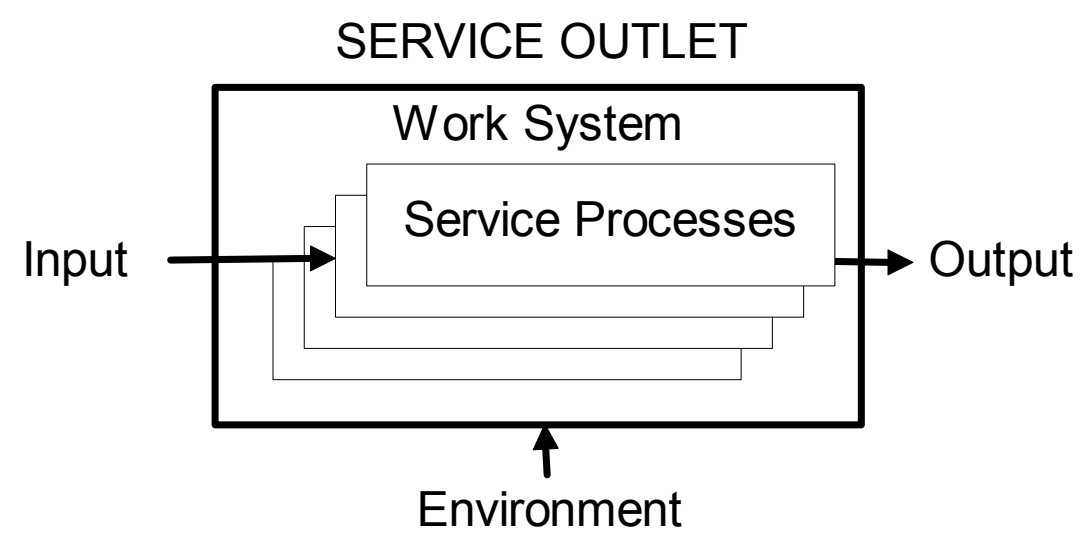

Figure 1. Work system centered model of service operations 


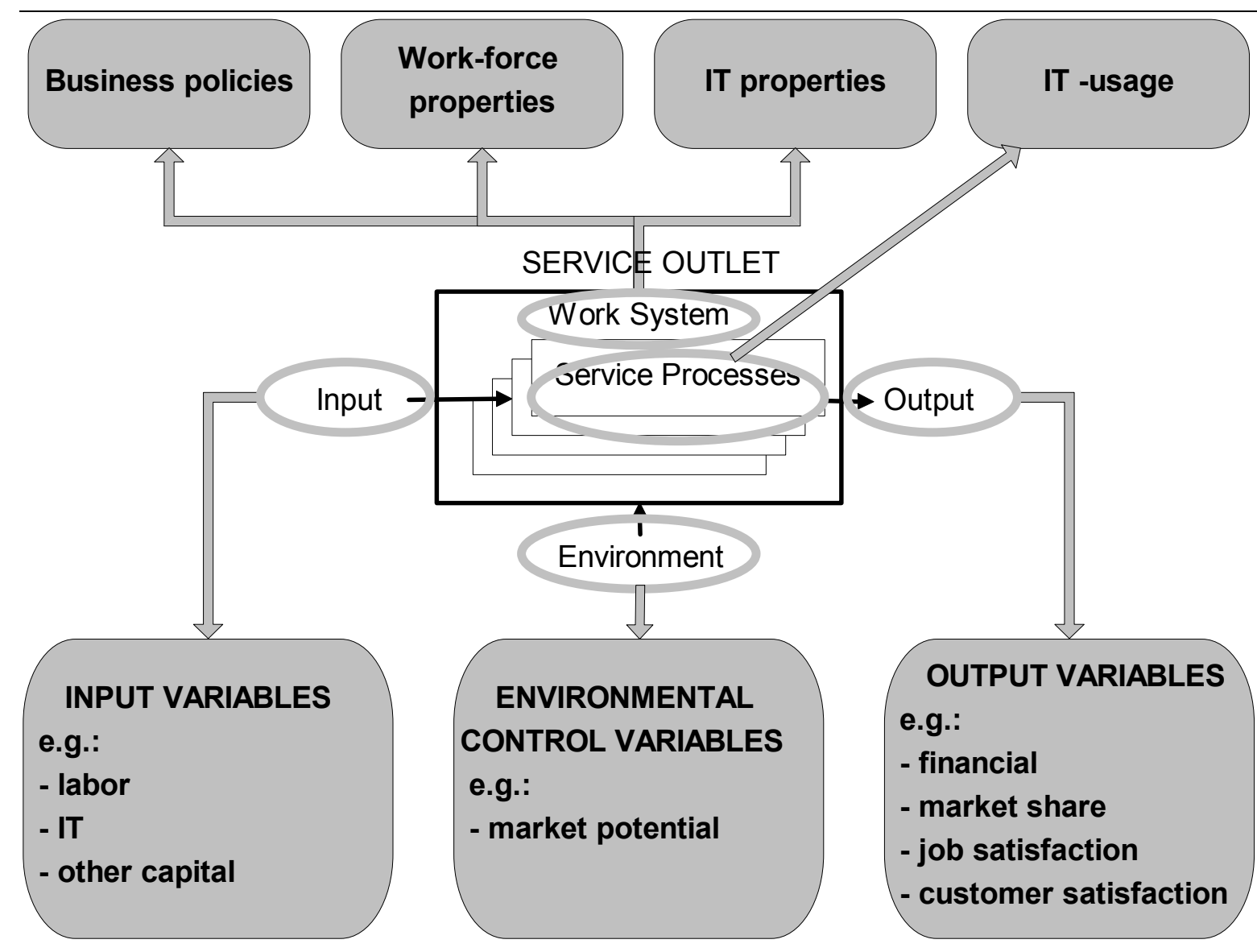

Figure 2. Variable Space 


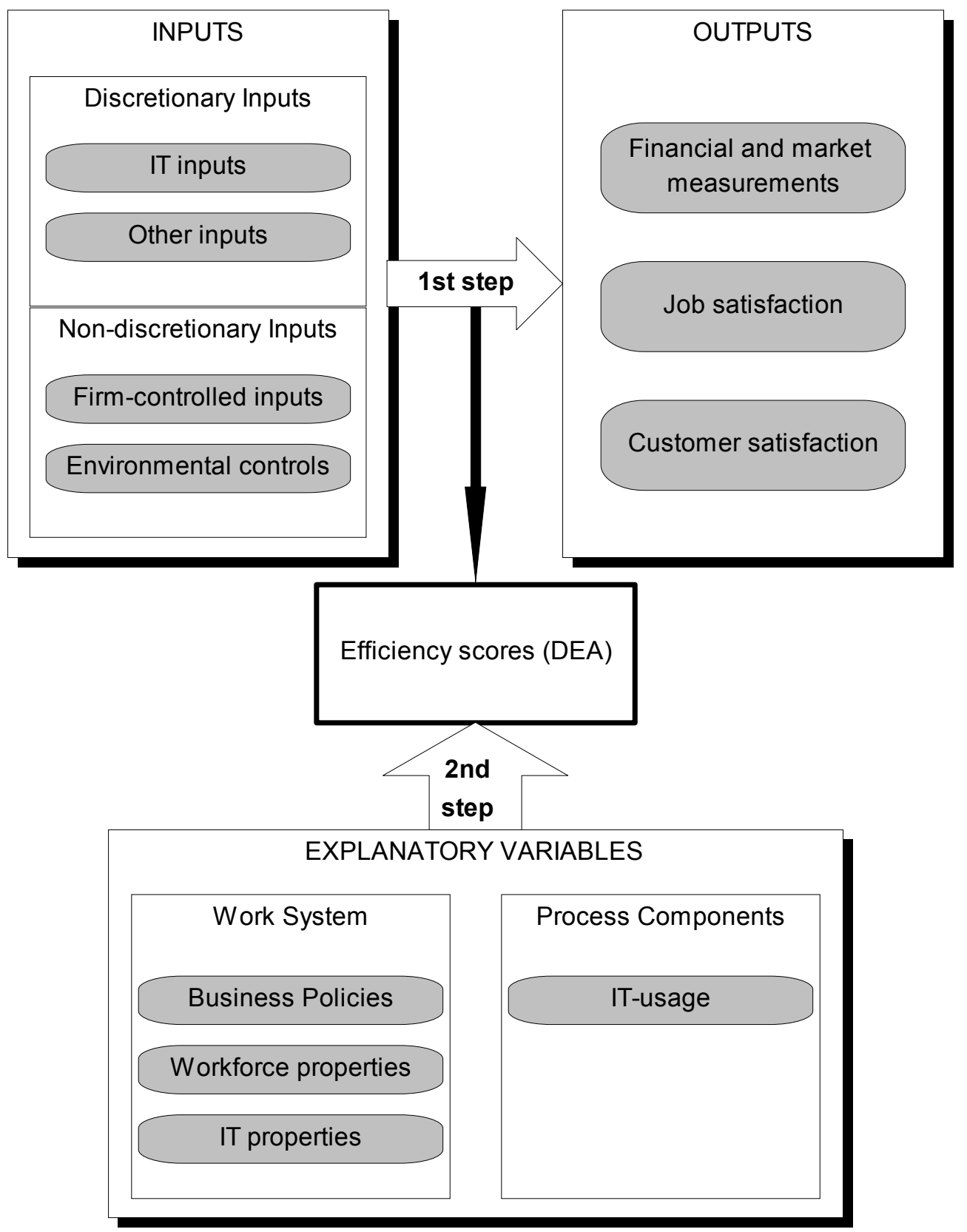

Figure 3. ITIMPACT methodology 


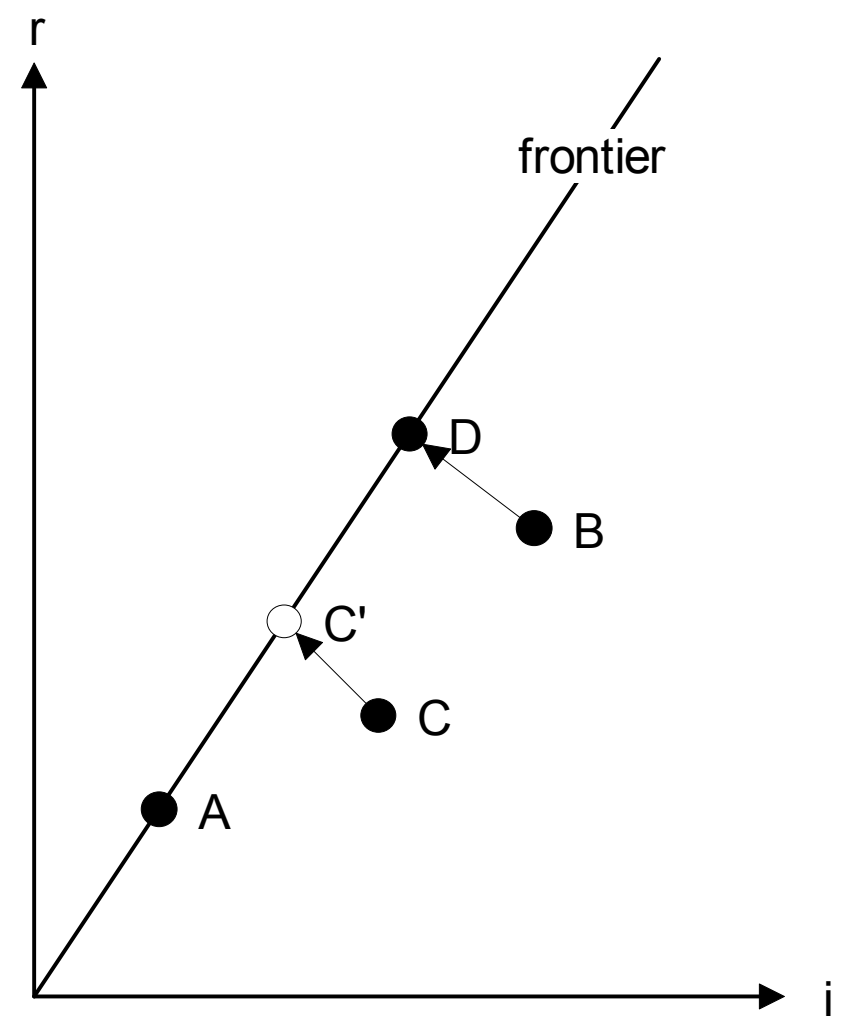

Figure 4. CRS frontier of one input (i) and one output (r) 